\title{
HOQTRÔNICAS COLABORATIVAS: O PROJETO IMPULSE FREAK
}

Fernanda Machado de Souza

Edgar Franco

\begin{abstract}
Resumo: A popularização das tecnologias computacionais altera de forma relevante as manifestações artísticas do final do século XX, proporcionando hibridações entre arte tradicional e as novas mídias, tornando o ciberespaço um ambiente fértil para experimentações artísticas. O presente artigo trata das questões que cercam a produção colaborativa em web arte, com ênfase na produção de HQtrônicas. Com esse objetivo traça um brevíssimo panorama das experiências colaborativas de arte na rede Internet, e foca nas construções colaborativas de histórias em quadrinhos eletrônicas, se detendo, finalmente, em uma análise mais pontual da HQtrônica coletiva Impulse Freak, um projeto da SITO.org - organização web que divulga artistas individuais e manifestações colaborativas desde 1997.
\end{abstract}

Palavras-chave: Arte em rede, web arte, colaboração, HQ̣trônica, Impulse Freak.

\section{NARRATIVAS EM TEMPOS DIGITAIS}

Iniciamos esse artigo com um dos questionamentos levantados nos estudos de Lúcia Leão (2004, p. 164): "a linguagem das novas mídias cria um ambiente fecundo para a produção, coleta, armazenamento e distribuição de narrativas?" Como a autora comenta, o ato de contar histórias é uma das peculiaridades dos seres humanos que os acompanham desde tempos remotos, que vem assumindo particularidades a partir das tecnologias agregadas a esse contar e a partir do próprio contexto no qual estão inseridos. Diversas são as formas de compartilhar e produzir narrativas: das narrativas orais passou-se às narrativas escritas, sedimentando e expandindo a memória, fixando enredos, ampliando o alcance das histórias; conta-se histórias com o teatro, com o jornal, com as histórias em quadrinhos ou cinema, por exemplo, cada um agregando características particulares ao ato de narrar e expandindo as possibilidades de experimentações. Passando ao contexto das narrativas no ciberespaço tem-se uma enorme gama de novos desafios e possibilidades a serem exploradas. Graças a suas peculiaridades,

Pode-se observar uma série de propostas instigantes emergindo no ciberespaço, se o considerarmos como uma rede dinâmica composta por pessoas e grupos, ambientes cíbridos (que integram simultaneamente o real e o virtual) além dos sistemas de informações, softwares e máquinas. (LEÃO, 2004, p. 165)

De fato é impossível pensar no final do século XX sem que se destaque o avanço tecnológico nos âmbitos da computação e das redes de telecomunicação, posteriormente acrescido da rede internet em específico. Como explica Gilbertto Prado (2003), os artistas inseridos em tais contextos passam a criar e narrar com esses meios agora disponíveis, passam a explorar as relações interpessoais em redes telemáticas, por mais

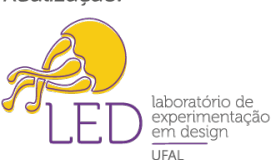


distantes que estejam uma da outra, e acabam por fazer emergir uma visão crítica sobre essa realidade tecnológica, ao mesmo tempo em que estimulam o desenvolvimento do imaginário social e coletivo. Ao explorar interatividade, informática e telecomunicações, explora-se a troca, a relação, o intercâmbio de experiências e visões.
A criação em rede é um lugar de experimentação, um espaço de intenções, parte sensível de um novo dispositivo, tanto na sua elaboração e realização como na sua percepção pelo outro. O que o artista de redes visa exprimir em suas ações é uma outra relação com o mundo: tornar visível o invisível, através e com um "outro", para descobrir e inventar novas formas de regulação com o seu meio, cujo funcionamento complexo coloca o indivíduo contemporâneo numa posição inédita. (PRADO, 2003, p. 25)

Duas características para que ocorra a manifestação artística em rede são a colaboração e a complementaridade. Do ponto de vista artístico, Prado (2003) destaca que as redes necessitam das pessoas em dois momentos ativos: ora como indivíduos expectadores, ora como co-autores em um sistema participativo no qual nos expressamos e realizamos intervenções. 0 trabalho em rede necessita, ainda, da complementaridade das pessoas envolvidas: "uma experiência de colaboração mútua é necessária para que os parceiros possam intervir de forma coletiva." (PRADO, 2003, p.31) Dessa forma, os envolvidos no processo precisam estar conectados nesse work in progress, em constante complementação, que conta com a contribuição de intervenções que carregam características artísticas individuais, particulares para se chegar a uma experiência comum a todos os participantes, enriquecida pela participação plural. $E$ ainda, enfatiza-se que "toda atividade artística em rede implica a presença, a perspectiva do outro; nossos sentidos apenas existem na medida em que eles são também uma doação do outro." (PRADO, 2003, p.36)

Os projetos de arte na rede, inicialmente, eram realizados a partir de experiências que contavam com a colaboração dos envolvidos para que se reunissem em um mesmo horário, utilizando-se de uma rede efêmera, organizada exatamente para a concretização dos projetos, especificamente. Isso acontecia pois a tecnologia utilizada normalmente composta por modems, computadores precários e telefones - possibilitava a comunicação pontual entre os indivíduos. Situados em diversos locais do mundo, todos deveriam se reunir em um mesmo momento para que o projeto se realizasse, como quando realizamos uma ligação por telefone, por exemplo - ambos participantes devem estar presentes para que a comunicação aconteça, cada um de um lado da linha.

Porém, a rede internet revoluciona a comunicação e os projetos em rede passam a existir em qualquer lugar e a qualquer tempo. A rede agora é permanente; os encontros, que se davam entre grupos restritos, agora são abertos ao público interessado; as ações na internet são facilmente localizadas através de ferramentas de busca e, mesmo que tenham data de início e fim, podem permanecer na rede para visitações futuras. $E$, de certa forma, respondendo à indagação inicial desse artigo, Prado destaca que "sobre muitos aspectos, no que diz respeito à criação, realização e divulgação, a rede se apresenta como um meio facilitador para a experimentação.” (PRADO, 2003, p.65)

A partir de então, de acordo com o autor (2003), os espaços de arte na rede passam a se configurar amplamente em dois aspectos distintos: sites de divulgação dos projetos de arte e sites que usam a própria rede como canal para realização dos projetos em arte. E esse segundo aspecto pode, ainda, se subdividir em: manifestações na rede disponíveis para que o usuário interaja com a interface criada; manifestações em que os multiusuários interajam entre si e participem de uma ação conjunta; e manifestações que apresentem uma interface criada para compor um projeto que não se limite à rede, como, por exemplo, uma web instalação.

O aspecto que mais interessa à abordagem desse artigo reside nas manifestações 
que incluem multiusuários interagindo entre si, participando de uma ação colaborativa online, fazendo emergir uma reflexão que conta com particularidades individuais para que se obtenha uma fruição do todo. Dois bons exemplos brasileiros que lidam com a colaboração do usuário em projetos de web arte ${ }^{1}$ são: Freakpedia², uma parceria dos artistas Fábio Fon e Edgar Franco; e Espelho Meu - Espanando pó de sua imagem³, de Fernanda Souza sob orientação, também, de Edgar Franco, ambos autores desse artigo.

O projeto Freakpedia, como descreve Fábio Oliveira Nunes (2010), artisticamente conhecido por Fábio Fon, nasce para refletir ironicamente sobre a ideia ilusória de espaço livre de colaboração na rede Internet em sites que usam a ferramenta wiki e contam com a participação do usuário para formar conteúdo. Em Freakpedia, qualquer informação de pouca ou nenhuma relevância é aceita pela administração do site sem se esperar nenhum rigor enciclopédico sobre o assunto, diferentemente do que ocorre em sites renomados como a própria Wikipédia, que posam de enciclopédia livre mas não conseguem obter real rigor sobre as informações que lá constam e rotulam o conteúdo como "relevante" ou "não relevante" através de uma equipe que não consegue ter critério e conhecimento globais sobre todos os verbetes lá inseridos.

\section{Como o artista comenta,}

Na verdade, há uma crítica celebrada que vai diretamente para a Wikipédia. Há um culto generalizado por grande parte dos entusiastas da rede em acreditar que a tecnologia wiki representa uma revolução de uma coletividade frente a um sistema homogêneo. De certa forma, essa tecnologia realmente pode ser capaz de criar estruturas menos rígidas e menos restritivas, mas o exemplo com certeza não cabe para a enciclopédia tida com "livre". Nela, ainda que não exista o papel de um poder centralizador, há um pensamento hegemônico que em nada difere daquele exercido em espaços convencionais. Não há uma mudança de valores e paradigmas e sim a tentativa de reproduzir a lógica dominante em seus conteúdos. (NUNES, 2010, p. 125)

Percebe-se claramente no projeto a preocupação dos artistas em refletirem sobre uma situação na qual todos os usuários no mundo estão submetidos, e a Freakpedia o faz através da participação colaborativa online: hoje o site conta com mais de 600 verbetes enviados por colaboradores que apoiam o projeto.

Espelho Meu funciona também a partir da interação com o site - um antiquário que, na prática, confronta os usuários de twitter com as imagens de si próprios projetadas virtualmente, na vida social online. A poética do projeto aborda, de forma mais abrangente, o papel do usuário em uma sociedade que migra do padrão industrial para o informacional, lidando com questões que tangem a construção do conhecimento em rede e a forma do usuário se relacionar e constituir conteúdo, assim como na Freakpedia, porém um conteúdo que é divulgado entre seus contatos e que acaba por constituir a sua imagem para eles.

Sobre a ação do indivíduo em si, diante da comunicação com as possibilidades que a virtualidade e a não identificação habitual do outro trazem, Rudiger (2011) trabalha com as palavras de Marc Guillaume, dizendo que

Em nível mais superficial, se trata em primeiro lugar de explorar a estranha liberdade de uma palavra privada nas instâncias de controle externo; palavra irresponsável, que pode oscilar entre a mentira e a verdade, misturar o real com a ficção; este jogo não é uma exploração do outro mas apenas dos papéis que se pode ter ao sermos outro. A dissimulação não leva senão a uma simulação pura, um travestimento textual, o eu parece ser o outro, embora neste jogo o sujeito possa eventualmente acabar sendo

\footnotetext{
1 "A produção em web arte necessariamente está ligada ao campo de significações que a Internet - em especial sua interface gráfica, a World Wide Web - suscita, como também às especificidades técnicas e conceituais que nelas se inserem." (NUNES, 2010, p. 119-120)

2 Disponivel em: http://www.freakpedia.org acessado em 22-07-2011.

3 Disponível em: http://tipof.com.br/espelhomeu acessado em 21-07-2011.
} 
apanhado numa armadilha de sua verdade: esta palavra, aparentemente livre, pode fazer surgir, em nível mais profundo, inconscientemente [individual e socialmente], o outro do sujeito. (GUILLAUME apud RUDIGER, 2011, p. 125)

Tomando tal contexto por base, trabalha-se no projeto com o indivíduo ator, que constrói uma gama de características pessoais e as divulga online. Tal usuário, então, é convidado a entrar em um antiquário, o Espelho meu, para que retire o pó de sua imagem; encontra seus últimos posts inseridos no ambiente e se depara com um questionário referente a sua atuação no twitter para descobrir se o "espelho" compraria a imagem que ele constrói. Certamente as respostas são brincadeiras com o indivíduo para que surjam questionamentos sobre o comportamento nas redes sociais e a imagem que se vende online, mesmo que inconscientemente.

Finalmente, o indivíduo tem a possibilidade de divulgar o projeto em sua rede de contatos através de uma integração do site com sua própria página do twitter. Portanto, é mais um projeto que lida com a construção do conteúdo por múltiplos usuários, que trabalha com a divulgação através da rede e tece reflexões sobre o comportamento do ser humano diante da vida social em rede.

\section{INTERNET, COLABORAÇÃO E QUUADRINHOS}

Além de tratar brevemente das manifestações em rede em um contexto mais amplo e incluindo aplicações em web arte, esse artigo enfoca as reflexões que ocorrem a partir de histórias em quadrinhos colaborativas que existem na rede Internet, ou são criadas a partir da troca de experiências online especificamente.

O avanço tecnológico computacional possibilita não apenas as experimentações telemáticas, como explicitado anteriormente, mas experimentações de criação utilizandose de recursos que iniciam os processos de hibridização das manifestações artísticas. No caso específico dos artistas que fazem parte do universo dos quadrinhos, em meados de 1980, iniciam-se experimentos de criação de narrativas utilizando-se dos recursos que o computador oferecia. Primeiramente, tais criações manuais foram reforçadas por ferramentas computacionais durante o letreiramento, a finalização ou colorização dos quadros da narrativa, ainda para fins de impressão. Aos poucos, o objeto impresso deixa de ser o foco de tais manifestações e as narrativas em quadrinhos passam do suporte papel aos browsers e monitores do computador, fazendo surgir essa nova narrativa híbrida entre HQ e hipermídia, denominada por Edgar Franco de HQ̣trônicas - termo que faz referência direta à história em quadrinhos eletrônica. (FRANCO, 2008, p. 15)

Dentre as características que as HQ̣trônicas assumem diante da relação com a hipermídia, a pesquisa de Franco (2008) destaca: a animação, a diagramação dinâmica, a trilha sonora, os efeitos de som, a tela infinita, a tridimensionalidade e, por último, a narrativa multilinear e a interatividade - e são essas as duas características que mais interessam o presente estudo, pois possibilita a união das HQ̣trônicas com a participação colaborativa em rede (em particular, a internet) e constitui o recorte escolhido da pesquisa.

Vale lembrar que quando acontece a união da produção de quadrinhos e a internet, observa-se um caminho gradativo que vai da comunicação para a promoção e, por fim, para a difusão digital em si, como comenta o autor e teórico dos quadrinhos Scott McCloud (2006). Esclarece-se, ainda, que essa difusão trata das "histórias em quadrinhos que circulam como informação pura entre produtor e leitor.” (MCCLOUD, 2006, p. 163) 0 autor complementa que enquanto escreve isto: 
Os quadrinhos na web ainda estão fazendo a transição da promoção para a difusão. Centenas de sites oferecem hoje informações sobre quadrinistas e sua obra, amostras de desenhos e distribuição online... E um pequeno mas crescente número de artistas está criando histórias destinadas exclusivamente à web. Os quadrinhos online ainda estão em sua fase de fronteira. Todo mundo praticamente escreve suas próprias regras. Como resultado, uma variedade de diferentes abordagens vem sendo testada na esperança de se encontrar ouro - mais estética do que financeiramente falando - ao menos pelo momento. (MCCLOUD, 2006, p. 165)

Mesmo que o processo de criação especificamente para a fruição na rede internet ainda esteja em uma fase emergente, muitas experimentações de narrativas já podem ser encontradas ao navegar-se pela web.

Dentre os projetos de quadrinhos que realmente fazem uso da rede internet e contam com a participação do público para que de fato aconteçam em sua plenitude, pode-se destacar a tira diária Slow Wave, desenhada por Jesse Raklaw. A narrativa ficcional final ainda é responsabilidade do autor e quadrinhista, mas seus leitores estão convidados a enviar as histórias de seus sonhos para que sejam desenhadas em formas de tiras e publicadas semanalmente. ${ }^{4}$

Sem dúvida, essa é uma forma muito interessante de utilizar a rede, aproveitando-se de sua característica de conexão global e da velocidade de transmissão de informações, o que permite ao autor receber diariamente relatos de varias partes do mundo. Em 2000, Raklaw lançou um álbum intitulado Dreamtoons, selecionando as melhores histórias de Slow Wave publicadas até aquela data. (FRANCO, 2008, p. 141)

No caso de Slow Wave, a narrativa por completo parte das características estéticas de Raklaw, único desenhista do projeto. Entretanto, algumas experiências colaborativas de quadrinhos na internet realizam experimentos baseados na contribuição de artistas variados, como é o caso do projeto nacional Copa dos Blogs.

O projeto conta com a participação de 28 artistas; cada um é responsável por escrever uma tira que tem como protagonista uma bola de futebol que percorre todas as tiras do projeto. O usuário da tira inicial, disponível no blog do primeiro artista, tem como opções "avançar no jogo" e descobrir por onde mais a bola vai passar, ou "voltar no jogo" e entender de onde a bola veio. Ambas as opções levam o leitor a outros blogs, de artistas diferentes, onde se encontra a próxima tira ou a tira anterior, dando a possibilidade do usuário de caminhar por todos os blogs e fruir a narrativa por completo.

O interessante é perceber a movimentação do usuário por diversos blogs, com narrativas que guardam particularidades estéticas e de humor que acabam por enriquecer a narrativa final como um todo. O projeto foi idealizado por Cleber B. e coordenado por Wesley Samp, ambos webquadrinhistas brasileiros. ${ }^{5}$

\section{IMPULSE FREAK E A COLABORAC̣ÃO DE FATO}

Como já demonstrado anteriormente, diversas são as possibilidades de experimentação com quadrinhos a partir da rede Internet e a colaboração. Porém, um projeto que de fato merece destaque diante das produções feitas é a HQ̣trônica Impulse Freak. Impulse Freak é um projeto da SITO.org, uma organização web que divulga artistas individuais e manifestações colaborativas; surgiu em 1997 e está alocada na seção Synergy dedicada a trabalhos coletivos dos associados ao site.

A HQ̣trônica pioneira carrega características de Slow Wave, por possibilitar que seus usuários participem da criação da narrativa, e envolve características, também

4 Projeto disponivel em: http://slowwave.com/ acessado em 23-07-2011.

5 Informações retiradas de: http://www.universohq.com/quadrinhos/2010/n18062010_09.cfm acessado em 24-07-2011. 
presentes no projeto Copa dos Blogs, por permitir a ação de diversos artistas e infinitas possibilidades estéticas. O grande diferencial do projeto é que qualquer usuário, sem restrições, após se cadastrar no SITO.org, pode enviar a seus próprios quadros para a continuação da história. Tem-se, portanto, uma narrativa de fato inspirada e executada coletivamente.

Além disso, de acordo com as análises de Franco (2008), trata-se de um projeto que carrega importância histórica por ser um dos primeiros a explorar as possibilidades da multilinearidade proporcionada pela hipermídia: ao fruir a HQ̣trônica, o leitor tem a sua disposição até dois quadros para seguir em frente, ou retornar ao passado, montando através de suas escolhas o caminho da narrativa. Essa multilinearidade narrativa de Impulse Freak caracteriza bem o que Ollivier Dyens descreve como a experiência de um projeto artístico em rede:

A arte da rede propõe um trajeto, certamente, mas um trajeto de exploração. As obras da rede se assemelham, de fato, às cerimônias religiosas: estruturadas e ritualizadas (para apreciar e compreender tais obras, é preciso conhecer um mínimo de dados técnicos), mas impossíveis de serem repetidas exatamente, existindo na navegação de cada usuário, desdobrando-se no aleatório e na surpresa de cada caminho que se toma. (DYENS, 2003 , p. 266-267)

A partir do projeto Impulse Freak, último caso destacado, foi possível de se constatar participações multiusuários em HQ̣trônicas colaborativas em três diferentes níveis:

1. Usuários participantes sem a certeza de que terão sua contribuição acatada, com a autoria clara do artista - quem executa e toma as decisões de criação (qual história desenhar, quais adaptações para que funcione em tira, qual estética utilizar, dentre outras);

2. Usuários que fruem por uma narrativa colaborativa fechada, que explora as características estéticas e de narração de cada artista participante do grupo de criação;

3. Usuários participantes da narrativa enquanto criadores da história e artistas propriamente ditos - são colaboradores que expõe suas características artísticas e reflexões, para que, ao final do projeto, integre uma peça comum de características singulares.

A internet possibilita uma vastidão de processos criativos e experimentações, portanto a intenção desse artigo não foi fazer um mapeamento quantitativo de manifestações artísticas, e sim qualitativo. Destacando-se exemplos que se complementassem e envolvesse tanto produções nacionais como internacionais.

Através dos exemplos trazidos, comprova-se a observação de Fábio Oliveira Nunes (2010):

\begin{abstract}
O tempo simultâneo e coletivo da rede viabiliza a existência de espaços colaborativos de participação mútua e conjunta entre os visitantes, seja através de dispositivos em espaços fisicamente distantes, seja em instalações tais quais espaços virtuais, onde o visitante pode ter indícios da presença de uma coletividade ativa - ou, em alguns casos, a telepresença instaurada. Há uma presença condicionada na poética do artista que pode tanto limitar-se a simplesmente oferecer caminhos múltiplos de navegação ou estabelecer convites para ações mais complexas, criativas e efetivas (NUNES, 2010, p. 120)
\end{abstract}

Essa afirmação corrobora a amplitude de possibilidades e riqueza das produções narrativas colaborativas em rede, a partir de projetos como a Impulse Freak, e nos instiga a como pesquisadores e criadores propormos trabalhos artísticos que explorem esse amplo campo de possibilidades aberto pela hipermídia. 


\section{REFERÊNCIAS}

DYENS, Ollivier. A arte da rede. In Arte e vida no século XXI: tecnologia, ciência e criatividade / Diana Domingues, organizadora. São Paulo: Editora UNESP, 2003.

FRANCO, Edgar Silveira. HQ̣trônicas: do suporte papel à rede internet. 2a edição. São Paulo: Annablume; FAPESP, 2008.

LEÃO, Lúcia. Cibernarrativas ou a arte de contar histórias no ciberespaço. In Derivas: cartografias do ciberespaço / Lúcia Leão, organizadora. São Paulo: Annablume; Senac, 2004.

MCCLOUD, Scott. Reinventando os quadrinhos. São Paulo: M. Books do Brasil Editora Ltda, 2006.

NUNES, Fábio Oliveira. Ctrl+Art+Del: distúrbios em arte e tecnologia. São Paulo: Perspectiva, 2010.

PRADO, Gilbertto. Arte telemática: dos intercâmbios pontuais aos ambientes virtuais multiusuário. 1ª edição. São Paulo: Itaú Cultural, 2003.

RUDIGER, Francisco. As teorias da cibercultura: perspectivas, questões e autores. Porto Alegre: Sulina, 2011.

Sobre os autores:

Fernanda Machado de Souza (mestra), Fasam e Faculdade Estácio - Goiás <fernandamsouza@gmail.com> Edgar Franco (doutor), Universidade Federal de Goiás <oidicius国gmail.com> 